\title{
MARCAS DE UMA ORIGEM E UMA PROFISSÃO: trabalhadoras domésticas peruanas em Brasília ${ }^{1}$
}

\author{
Delia Dutra*
}

\begin{abstract}
O presente artigo analisa como um grupo de mulheres peruanas, trabalhadoras domésticas, vivencia sua experiência migratória em Brasília. A análise é desenvolvida em uma perspectiva interacionista - com ênfase nas dimensões de gênero, étnica e de classe - facultando compreender os processos de integração social dessas migrantes numa cidade com características históricas e urbanas particulares no Brasil e na região. As entrevistas em profundidade possibilitam refletir sobre como elas explicam a sua integração à cidade, o dia-a-dia no trabalho; ou seja, analisamos como produzem o seu espaço de vida em migração. Podemos estabelecer, nessa condição de migração a trabalho, uma variedade de elementos que concorrem para a produção desse espaço: a origem social e cultural, as relações sociais de gênero dentro e fora do núcleo familiar, dentre outros. Identificamos um forte vazio de honra e a falta de estima social associados pelas próprias migrantes à profissão de trabalhadora doméstica.

PALAVRAS-CHAVE: Mulheres peruanas. Brasília. Trabalho doméstico. Interações cotidianas.
\end{abstract}

\section{INTRODUÇÃO}

As mulheres representam quase a metade do total mundial de migrantes internacionais, chegando, inclusive, em alguns continentes, a ultrapassar a quantidade de homens migrantes. Contudo, a falta de um marco legal adequado às necessidades das mulheres migrantes no mundo as torna mais vulneráveis e muito mais expostas aos riscos decorrentes da mobilidade. Segundo Thompson da International Organization for Migration (IOM):

[...] apesar de as políticas de migração para trabalho nos países de destino parecer neutras no que tange ao gênero, elas continuam a ter um viés e embasamento num modelo focado nas habilidades e trabalhos tradicionalmente masculino. Mais oportunidades para migrar legalmente, acrescenta Thompson, ajudariam a prevenir o envolvimento (involuntário)

* Doutora em Sociologia pela Universidade de Brasília. Professora Colaboradora Plena e Bolsista do Programa Nacional de Pós-Doutorado (PNPD/CAPES) no Programa de Pós-Graduação em Estudos Comparados sobre as Américas (CEPPAC), Universidade de Brasília. Pesquisadora do Observatório das Migrações Internacionais e do Laboratório de Estudos sobre Migrações Internacionais (LAEMI). Asa Norte. Cep: 70910900. Brasília - Distrito Federal - Brasil.deliadutra@gmail.com

${ }_{1}^{1}$ Pesquisa realizada na cidade de Brasília entre os anos 2008 e 2011. de muitas mulheres em situações irregulares, de $e x$ ploração e abuso. ${ }^{2}$

As sucessivas crises mundiais, de acordo com Hirata (2010), têm gerado muitas análises; porém, muito poucas estão voltadas para compreender os impactos sobre os homens e sobre as mulheres. A precarização do trabalho da mulher é mais evidente do que a do homem, gerando maior impacto na precarização familiar.

Ou seja, isso traz implicações, não só para a própria mulher como para o núcleo familiar, gerando mudanças na estrutura social, com enormes repercussões na comunidade local (de origem) e que provocam fenômenos como o da mobilidade indesejada da mulher, afetando a estrutura da família de matriz patriarcal. ${ }^{3}$

2 Tradução nossa do original em inglês. Destaques nossos. IOM - International Organization for Migration Gender and Migration News. Issue 34, April 2010. Disponível em: http://iom.int. Acesso em mai. 2010

${ }^{3}$ Fontenla (2007, p. 258) define o patriarcado como "sistema de relações sociais sexopolíticas baseadas em diferentes instituições públicas e privadas e na solidariedade interclasses e intragênero instaurada pelos homens, que, enquanto grupo social e em forma individual e coletiva, oprimem às mulheres também em forma individual e coletiva, e se apropriam de sua força produtiva e reprodutiva, de seus corpos e seus produtos, seja com meios pacíficos ou por meio da violência (Tradução nossa do original em espanhol). 
Nesse sentido, a pobreza da mulher propicia uma maior violência para com ela e seus dependentes. Provoca a separação, o afastamento da mulher do seu núcleo familiar, seus afetos e sua cultura, submetendo-a a empregos onde pode sofrer violência física e/ou simbólica. A questão é que o processo de globalização, segundo Hirata (2010), criou mais empregos para as mulheres, porém, trata-se de empregos vulneráveis e precários.

Seguindo essa linha de pensamento, à categoria 'mulher migrante' podem ser associadas outras categorias, como a de 'trabalhadora doméstica', por exemplo, elemento que demanda do/a leitor/a operações cognitivas de classificação e categorização adicionais. Ao pensarmos as mulheres migrantes trabalhadoras domésticas originárias do Peru e residentes em Brasília - no período de 2008 a 2011, podemos, rapidamente, associá-las à situação de pobreza, desemprego, exclusão social, falta de oportunidades, pouca ou inexistente educação formal etc.

No entanto, elas poderiam, também, ser pensadas como mulheres empreendedoras, determinadas a superar limites materiais e emocionais para melhorar de vida. Mulheres capazes de tomar decisões, apesar das poucas alternativas que possam ter ao longo das suas vidas. Dito de outra forma, mulheres que pro今. daquela chance de trabalho que alguém lhes falou existir numa cidade como Brasília. sua própria família.

O presente artigo analisa como um grupo de mulheres peruanas, trabalhadoras domésticas, vivencia sua experiência migratória na cidade de Brasília. A análise é desenvolvida em uma perspectiva interacionista, facultando compreender os processos de integração social dessas migrantes numa cidade com características históricas e urbanas particulares no Brasil e na região. Nessa instância, desenvolvemos nossas reflexões com base na dimensão de gênero, i.e. a condição de serem mulheres, sobre a qual se sobrepõem outras dimensões que afetam a experiência de vida em migração: a origem étnica e de classe.

Identificamos um forte vazio de honra e falta de estima social associados, pelas próprias migrantes, à profissão de trabalhadora doméstica. Apesar disso, as migrantes dão continuidade aos seus projetos e sonhos alimentando, dessa forma, o trabalho diário e as estratégias de sobrevivência.

Organizamos o texto em cinco partes, além da introdução e da conclusão. Na primeira, refletimos sobre as implicações de termos escolhido realizar entrevistas em profundidade com dez mulheres migrantes; i.e. como a memória, as lembranças e a própria situação de entrevista é entendida nessa pesquisa. A segunda parte explica as singularidades desse fluxo migratório e o contexto social e cultural da cidade, país e região em que se deslocam. A cultura de origem das migrantes é analisada na terceira parte, levando em conta a importância do lugar de origem para compreender as especificidades desse processo migratório. $\mathrm{Na}$ quarta parte, levantamos uma discussão teórica, em diálogo com as perspectivas das próprias migrantes, sobre a dimensão étnica e suas implicações, não somente com o presente vivido, senão com aquilo que lembram, sonham e projetam. Na quinta e última parte, levantamos uma discussão sobre o que consideramos que são marcas femininas, que as próprias migrantes verbalizam na hora de explicar, por exemplo, de que modo começam 
suas histórias de cuidar dos outros, quais as condições de vida-trabalho atuais, quais as implicações da vida privada na profissão de trabalhadoras domésticas migrantes. Assuntos esses que nos conduzem a discutir o conceito de classe desde uma perspectiva weberiana, pois isso nos permite problematizar sobre a honra e o status associado à profissão por elas desempenhada nesses anos de migrantes.

\section{SOBRE FALAS, LEMBRANÇAS E SENTIDOS}

Eu tenho uma história para te contar. Não sei se você quer que eu te fale agora, mas ontem não conseguia dormir enquanto lembrava e pensei: isso devo contar para ela, já que ela gosta de estudar as histórias das mulheres (Amelia). ${ }^{4}$

"Propor-se não lembrar é como se propor não perceber um cheiro, porque a lembrança, assim como o cheiro, acomete, até mesmo quando não é convocada" (Sarlo, 2007, p. 10). A capacidade de lembrar, muitas vezes, acontece de forma quase automática, isso porque, "Antes de ser atualizada pela consciência, toda lembrança 'vive' em estado latente, potencial” (Bosi, 1994, p. 51).

A lembrança é estimulada por elementos externos, às vezes, quase imperceptíveis. É estimulada pelos outros que perguntam ou que provocam porque não perguntam nem olham nos olhos, pelos cheiros da rua ou pelo próprio cheiro da migrante que se altera, pois a comida muda, a língua muda, a cidade é outra; i.e., a lembrança é interação.

A memória possui um caráter social, no sentido de que ela existe em relação a pessoas, momentos, palavras, ideias. A memória de cada uma das migrantes vai sendo configurada a partir de uma memória coletiva que, se-

${ }^{4}$ Foram dez as mulheres migrantes peruanas entrevistadas. Ao longo do texto são resgatadas falas das próprias migrantes no intuito de ilustrar e ajustar nossa reflexão e análise. Note-se que, tal como foi combinado com as migrantes que contribuíram com nossa pesquisa, os seus nomes são fictícios, buscando, com isso, preservar suas identidades. guindo a Halbwachs (1990), estaria demarcada pelo tempo e o espaço - esses dois últimos entendidos como construções sociais, e, também, pelas memórias individuais.

O exercício das migrantes de lembrar, de narrar e de projetar permite-nos analisar e problematizar a riqueza dos sentidos por elas produzidos a respeito da experiência migratória em Brasília. Isso porque, seguindo a proposta metodológica interacionista, entendemos que indivíduos com uma origem cultural comum e que moram numa mesma cidade ou num mesmo bairro podem ter visões de mundos diferenciadas, já que a natureza do meio em que se vive é dada pelo significado que cada uma lhe confere (Blumer, 1998). Ou seja, os significados que elas outorgam ao seu passado, presente e futuro, nesse momento de vida de trabalhadora doméstica em migração.

O universo de análise em profundidade da pesquisa se constitui pelas narrativas de dez mulheres migrantes - trabalhadoras domésticas originárias do Peru - articuladas com elementos recolhidos em fases anteriores de observação livre e observação metódica. ${ }^{5}$ A

[...] nossa reflexão sobre este fenômeno não ficou restrita às entrevistas, porque consideramos que a entrevista por si só, como única técnica de aproximação à realidade das migrantes, tem suas limitações para captar, compreender e interpretar os significados dados pelas próprias mulheres a sua situação de trabalhadoras domésticas, migrantes em Brasília. É evidente que as entrevistas dão um grande sustento às nossas reflexões, porém o tempo todo se estabelece o diálogo, como já mencionamos, com elementos observados inicialmente nas fases anteriores de observação e interação com um grupo maior de migrantes (um total de 19) e com a pesquisa teórica que realizamos ao longo de todo o processo (Dutra, 2013, p. 137).

${ }^{5}$ Com base em Granai (1969), identificamos três fases na nossa pesquisa de campo. Primeira, a "observação direta livre”, primeira aproximação para conhecer como vivem essas migrantes e quais as particularidades do fenômeno em Brasília. Segunda, "observação direta metódica”, após a primeira fase estamos em condicões de reconhecer limites e recortar o objeto a ser estudado. Terceira, a "observação clínica”, na qual desenvolvemos um diálogo direto, prolongado e em profundidade com o grupo de dez migrantes. Essa última fase aconteceu entre março e outubro de 2009, e entre abril e dezembro de 2010. Para mais detalhes sobre a pesquisa, consultar Dutra (2013), capítulo 3. 
Significa dizer que o foco da pesquisa está no âmbito do microssocial, ${ }^{6}$ sem esquecer que a agregação das ações dessas dez mulheres provoca outros e diversos acontecimentos, cujos efeitos ou consequências chegam a se manifestar no nível do macrossocial e vice-versa.

As entrevistas em profundidade, realizadas junto às dez migrantes com mais de três anos de residência na cidade, possibilitam refletir sobre como explicam a sua integração à cidade, o dia-a-dia no trabalho, o sentido de estarem afetadas pelas suas histórias passadas e pelos projetos futuros. Nesse sentido, analisamos como produzem o seu espaço de vida em migração. Podemos estabelecer, nessa condição de migração a trabalho, uma variedade de elementos que concorrem para a produção desse espaço: as motivações individuais, as relações familiares, a origem social e cultural, o grupo de referência, o status da profissão, a experiência urbana no presente e passado e as relações sociais de gênero dentro e fora do núcleo familiar.

Dessa forma, definimos alguns eixos fundamentais que serviram de guia para as entrevistas: a origem (lembranças da infância e juventude, família deixada na terra de origem), a família hoje (relacionamento, questão financeira, ressignificações dos afetos), o Bras sil (destino escolhido ou não, pré-noções sobre స్ o país) e Brasília (a cidade, as interações com os locais, os espaços públicos e o acesso aos สี่ serviços), o trabalho (interações cotidianas, perspectivas, remuneração, espaço e isolamento), ser mulher (na dinâmica do passado-presente-futuro).

Esses eixos foram definidos no intuito a de, quando necessário, motivar a fala das mi-

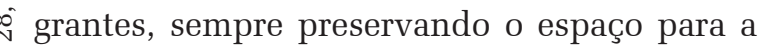
$\therefore$ espontaneidade. Isto é, motivar a migrante a falar sobre tal tópico desde que possamos encontrar um nexo com o que está sendo relatado; o que também nos permite descobrir o que elas têm para nos dizer que não foi por

${ }^{6}$ Trata-se de uma pesquisa que não objetiva a representatividade estatística. nós antes pensado, e sim, possa nos ajudar na pesquisa. Isto é, descobrir, junto com elas, seus quadros de referências, que, em diálogo com o contexto social, político e econômico do país de origem e as condições de vida em Brasília, nos permitem desenvolver uma reflexão sociológica compreensiva deste fenômeno.

Dito de outra forma, desenvolver uma reflexão sociológica e epistemológica que, nas palavras de Michel Thiollent (1987, p. 81), corresponderia a “[...] uma 'sociologia' da situação de entrevista para uma avaliação da relevância da informação captada e suas distorções".

Isso porque o relato, na instância da entrevista, evidentemente, não é o ato "puro" da interação vivida e que está sendo relatada pela migrante - porque, aliás, essa tal "pureza" do ato "original" inexiste como objeto científico. Mas é justamente aí que está nosso ponto de interesse: acionar sua memória para que, assim, ela relate suas vivências, reconstruindo suas experiências, dando ela própria sentido àquilo vivido. Considerando que, em consonância com Woortmann (1997, p. 111), “[...] não se deve esquecer que a memória é seletiva; ao dar presença ao passado, o faz nos termos do presente. [...] A memória tanto opera pela recordação como pelo esquecimento, respondendo às necessidades do presente".

Daí sustentarmos que os significados que todo ato de interação detém para um indivíduo são resultado de processos de interação prévios (o já vivido, memória) e da interpretação própria (self interaction ${ }^{7}$ ), também formada no contexto de interação social (Blumer, 1998). Por isso, esses sentidos ou significados que aparecem nos relatos das migrantes, conforme entendemos, são um produto social, ou seja, um resultado de suas experiências de vida (de interação), não só com os outros (indivíduos), mas, também, com valores, crenças, hábitos

\footnotetext{
${ }^{7} \mathrm{Na}$ proposta metodológica do interacionismo simbólico, desenvolvida por Blumer (1998, [1937]), o autor sustenta que o ser humano, não só é um agente social que responde, como, também, dá pistas aos outros nos processos de interação e de auto-interação (self interaction), pois, como ser social, o indivíduo é capaz de estabelecer interação
} consigo próprio. 
(self interaction) que vão sendo transformados durante a vida da pessoa como consequência do seu processo de individualização.

\section{CONTEXTO E SINGULARIDADES DO FLUXO MIGRATÓRIO}

Fundada em 1960, Brasília recebeu sempre importantes fluxos de migração e foi por isso considerada um "microcosmo da cultura brasileira”, mantendo sempre sua capacidade de atração de fluxos migratórios de diferentes regiões do país. Ela já foi vista pelo resto do país como a "ilha da fantasia", por deter um padrão social menos injusto do que a média nacional (Nunes, 2004, p. 14). Contudo, nesses últimos anos, o Distrito Federal $^{8}$ apresentou um aumento da distância entre ricos e pobres.

Por seu lado, o Brasil, hoje a maior economia da região, veio se tornando um destino cada vez mais atraente para migrantes dentro do continente. Historicamente, o país ofereceu e continua oferecendo melhores condições de trabalho para profissionais e migrantes qualificados da região. No entanto, de acordo com Sala (2008), a partir da década de 1990, o Brasil emerge com mais força como uma opção já não só para migrantes qualificados de países do Cone Sul, mas, também para aqueles com nível de escolarização mais baixo.

Dentre os motivos citados por essa autora estão: o crescimento da taxa de desemprego na Argentina, Bolívia, Paraguai e Uruguai; a diminuição do desemprego no Brasil; a menor procura por trabalhadores temporários para o setor da agricultura na Argentina; o elevado crescimento demográfico da Bolívia e do Paraguai; a diminuição das alternativas de trabalho na fronteira paraguaio-brasileira e a redistribuição da população desde o planalto andino-boliviano para regiões próximas à fronteira

8 Cf. http://www.unb.br/noticias/unbagencia/artigo.php?id =288, e o comunicado do IPEA em: http://www.ipea.gov.br/ portal/index.php?option $=$ com content\&view $=$ article\&i $\mathrm{d}=1796 \% 3$ Acomunicado-do-ipea-2010-julho-no-58\&cati$\mathrm{d}=161 \% 3$ Apresi\&Itemid =1. Acesso em: 15 jan. 2014 com o Brasil (Sala, 2008, p. 75).

O início do fluxo migratório internacional de mulheres para Brasília, com este perfil específico - migrantes de países da região, que vêm à procura de emprego no setor de serviços domésticos - poderia estar associado aos primórdios da cidade de Brasília, à medida que foram se estabelecendo na cidade representantes do corpo diplomático dos mais diversos países. Com alguns deles chegavam mulheres empregadas no serviço doméstico da família.

As próprias migrantes entrevistadas relatam histórias de outras que as precederam acompanhando tais famílias. Notadamente, destacam-se os diplomatas originários dos países andinos como os que possuem mais o hábito de chegar com suas próprias empregadas. Sem dúvida, isso passa por uma prática cultural de origem, onde a empregada é, em certa forma, 'propriedade' da família e, junto com ela, se desloca. Tais práticas, entendemos, estão diretamente afetadas pelos altos níveis de pobreza, desigualdade e falta de oportunidades que afetam países como o Peru e, particularmente, a mulher de origem indígena. Posto que

[...] a pobreza é um fenômeno que se encontra diretamente relacionado aos níveis e padrões de emprego e às desigualdades existentes na sociedade. [...] O gênero e a raça/etnia são fatores que determinam, em grande parte, as possibilidades de acesso ao emprego, assim como as condições em que esse se exerce (OIT, 2005, p. 3).

Consideramos aceitável essa ideia, manifestada por nossas entrevistadas, para explicar como ou por que se inicia esse fluxo migratório para Brasília, uma cidade nem muito conhecida no contexto de origem dessas migrantes, e, aparentemente, uma cidade que oferece poucas chances de ascensão social, ou seja, de melhoras no que diz respeito tanto ao tipo de função a ser desempenhada quanto à interação com outros grupos sociais para além daquele das migrantes trabalhadoras domésticas hispanofalantes.

Evidentemente, estimamos que esse fluxo migratório para Brasília foi sendo configu- 
rado de forma gradual. No início, umas poucas que chegavam junto às famílias que as empregavam, também originárias do mesmo país. Famílias que, por pertencerem ao corpo diplomático, se beneficiam da possibilidade de outorgar o que se denomina de "visto cortesia" tanto para integrantes da própria família quanto para as pessoas que para elas trabalham (trabalhadoras domésticas, seguranças etc.).

À medida que foi passando o tempo, aquelas migrantes, pioneiras no trabalho doméstico junto às famílias dos diplomatas, foram trazendo outras mulheres da família ou amigas e ajudando a colocá-las em famílias conhecidas dos seus empregadores. Dessa forma, surgem, também, os diplomatas de origem europeia, norte-americana, assim como famílias brasileiras vinculadas à diplomacia ou a altos cargos em empresas ou organismos internacionais ou do próprio governo, que começam a se interessar pela possibilidade de empregar em casa uma trabalhadora doméstica estrangeira e já não mais uma brasileira. Isso porque para alguns existem claras vantagens.

Nós preferimos as peruanas, pois elas são menos sindicalizadas [do que as brasileiras], mais responsáveis e dedicadas. Estão determinadas a melhorar de vida. Elas não querem para os seus filhos a vida que os seus pais deram para elas. Isso resulta numa atitude de maior compromisso com o trabalho (Emจ uma conversa por ele solicitada).

\section{CULTURA ANDINA: origens e este-} reótipos

Minha mãe sempre falava, a mulher tem que ser semente, e também coluna da família. Se ela não lutar pela construção da casa própria, o homem nunca vai pensar nisso (Elena)

${ }^{9}$ Visto que permite permanecer, temporalmente, no Brasil sob a responsabilidade daquela pessoa que assina (diplomata), assumindo a proteção e segurança do contratado. É concedido por um período curto, no qual deve ser renovado caso o responsável (empregador) deseje fazê-lo. Caso desista de manter a concessão do visto, o empregador deve garantir os meios para o/a contratado/a retornar ao país de origem.
A cultura andina tem, nas suas origens, o Império Inca (e período pré-incaico), assim como diversos grupos étnicos que existiram nos territórios hoje ocupados pelo Peru, Bolívia, Equador, sul da Colômbia, noroeste da Argentina e norte do Chile entre aproximadamente o ano 1200 e a invasão dos espanhóis no continente, século XVI (Lumbreras, 1990).

Nesse contexto pré-colombiano, muitos documentos da época evidenciam a alta posição econômica e religiosa da mulher incaica, ou seja, ela não era considerada um ser inferior. Ao contrário, estudiosos falam da existência de um "paralelismo sexual" que outorgava tanta importância à mulher quanto ao homem. Análises de representações gráficas, assim como de versos escritos e elaborados na época sobre ou, para, os deuses demonstram a crença em divindades bissexuais, e não, exclusivamente, masculinas ou femininas (Harrison, 1985, p. 13). ${ }^{10}$

Existia, também, o direito a herdar tanto para homem quanto para a mulher, porém todo esse sistema foi sendo modificado com a chegada dos colonizadores espanhóis. Rapidamente, a potência colonizadora foi transformando e impondo sua lógica patriarcal de organização social, dando como resultado situações como a que descreve o sociólogo peruano Hildebrando Castro Pozo (apud Harrison, 1985, p. 15): ${ }^{11}$

[...] [atualmente] um fato comum que pode ser observado na serra [...] quando descem das punas ${ }^{12}$

10 Resulta-nos interessante mencionar que essa leitura do lugar da mulher na cultura indígena andina pré-colombiana não é consenso e existem outras abordagens analíticas sobre esse assunto. Por exemplo, Montaner (2001), ao fazer uma análise geral do processo de colonização espanhol, sustenta que a sociedade patriarcal dos espanhóis encontrou na América a sociedade patriarcal dos índios. Para esse autor, mesmo que a realidade dos astecas não fosse a mesma que a dos incas, isto é, reconhecendo que cada grupo étnico tinha suas especificidades, a mulher ocupava um lugar inferior ao do homem. No entanto, nós privilegiamos o ponto de vista de Harisson (1985), que baseia seu pensamento em estudos específicos sobre a realidade de grupos indígenas habitantes do território que hoje ocupa o Peru; assim como, também, por levantar questões como a do paralelismo sexual nesses grupos, que, raramente, costumam ser mencionadas e se tornam muito significativas para nossa pesquisa.

${ }^{11}$ No seu livro "Nuestra comunidad indígena” publicado em 1924 e em 1979.

${ }^{12}$ Do quéchua, significa terra alta e fria. Cf. http://www.katari.org/diccionario/diccionario.php. Acesso: 28 jan. 2014. 
para as feiras: os homens andando [a pé] ou montados em burros, sem outra carga além de suas mantas e petaca-carteras ou "chuspas" de lã não muito cheias de coca; enquanto que as mulheres, carregadas como bestas, levam dentro do "quipe" todos os produtos que vão vender [...]. Não tenho conseguido constatar um só caso em que um burro ou um homem desçam carregados e sua companheira tão somente com o fruto do carinho "quipichado". ${ }^{13}$

Observe-se, também, que, no Peru, há um ditado popular que diz o seguinte: el que no tiene de inga tiene de mandinga, segundo explica o antropólogo peruano Luis Lumbreras. Inga são os índios, e mandinga aqueles que têm sangue africano. O Peru, segundo o antropólogo, é quase um mostruário de todos os países do mundo, não só pela paisagem, mas, sobretudo, pelo povo (Lumbreras, 1990, p. 58).

No meu país não tem uma raça determinada. Não temos ... como dizer "são brancos... são indígenas...". Na minha família, na verdade, eu não sei. Não sei exatamente... o que sim sei é que meu avó paterno era um homem alto com traços chineses. E o meu pai também tinha esses traços. Meus irmãos, alguns deles, também. Eu não, não puxei a ele. Na família do meu pai... conheci uns primos... e eram assim... não brancos exatamente... mas colorados, com o cabelo bem 'rojizo'. A família da minha mãe... eu lembro do seu pai, um homem baixinho, fininho, branco. Da mãe dela, não lembro, praticamente não conheci (Elena).

Essa múltipla composição faz com que o processo de identificação e de definição daquilo sentido como próprio pelos peruanos seja muito complexo, algo característico da realidade de muitos países latino-americanos. Logo aparece o argumento dos ancestrais reconhecidos no antigo mundo andino, o período incaico ou pré-incaico. Porém,

[...] essa identificação resulta forçada, romântica e não pode ser aceita sem analisar as relações concretas que aquela época tem conosco, habitantes de um país onde além de "ingas" temos "mandingas" e de outros povos da Europa, do Oriente, e todos acabamos nos considerando "peruanos", mesmo que os hispano-falantes não se compreendam com os qué-

${ }^{13}$ Tradução nossa do original em espanhol, mantendo as palavras em língua quéchua. chua ou os aymara-falantes [...] (Lumbreras, 1990, p. $58-59) .{ }^{14}$

Esses elementos mais recentes, tanto os apontados por Castro Pozo e por Lumbreras, assim como os das próprias mulheres peruanas que contribuíram com a pesquisa, continuam evidenciando o dinamismo da configuração social, histórica, cultural do lugar da mulher nessa cultura indígeno-andina, com forte tradição camponesa, mas que, hoje também, está perpassada - no grupo de migrantes aqui estudado - pela experiência da migração interna e vivência de anos na grande cidade (do interior para Lima, capital do Peru). Observemos que, do total de dez mulheres entrevistadas, oito nasceram no interior do Peru e vivenciaram experiências de migração para a cidade de Lima, a capital, quando crianças ou adolescentes.

Isso tudo nos permite começar a avançar na nossa compreensão dos relatos das migrantes na hora de falar e explicar, por exemplo, por que são elas que migram e não os maridos, ou a família em conjunto; como foram tomadas as decisões e como continuam sendo tomadas hoje, em relação ao dinheiro enviado ou à educação dos filhos, dentre outros assuntos.

Para a mulher é muito mais fácil arrumar emprego onde for. Se você estiver numa situação difícil, sendo mulher pode trabalhar até em casas [doméstica]. Já o homem... não. Ele não se acostumaria com esse tipo de trabalho. Então a mulher migrante tem como opção trabalhar em casas (Elena).

Tenho refletido e pensado muito no assunto. Vejo que antes, na minha vida no Peru, eu passei só cuidando dos outros, incluindo ele [marido], às vezes até como se fosse um filho ou um irmão. Então agora as coisas mudaram, os sentimentos mudaram. Sempre ficava preocupada com os outros e esqueci minha própria vida; isso dói, e me sinto tão sozinha, não ter com quem desabafar tudo isso que sinto é difícil (Teresa).

Já passaram 7 anos, eu sinto muito mais falta dos meus filhos do que do meu marido. E depois de tanto tempo, sei que nem sempre já dá para confiar nele [o marido]. Aí... ultimamente eu prefiro enviar

${ }^{14}$ Tradução nossa do original em espanhol. 
dinheiro no nome do meu filho mais velho e não do meu marido. Mas às vezes mando alguma coisa para ele [marido], porque acho que já percebeu e fica bravo comigo (Amelia).

Podemos observar, nesses relatos, uma complexa mistura entre traços tênues de uma cultura milenar, com aqueles da cultura patriarcal do colonizador espanhol e, finalmente, com uma realidade contemporânea internacional mais urbana e fortemente marcada por uma divisão sexual e internacional do trabalho, mas que ainda está perpassada por elementos de uma cultura indígena.

\section{IDENTIDADES, GÊNERO E FRON- TEIRAS SOCIAIS ÉTNICAS}

$\mathrm{Na}$ teoria antropológica, foram desenvolvidos dois modelos básicos de interpretação da etnicidade. Por um lado, o primordialista, que toma como referência a antropologia de Clifford Geertz, que desenvolveu um modelo de etnicidade como fator existencial da condição humana, como algo não escolhido, algo dado pelo fato de ter nascido numa comunidade. Por outro, o situacionista ou instrumentalista, que toma como referência a obra coletiva dirigida por Frederik Barth (2008) e associa a s etnicidade com movimentos de afiliação ou id identificações que oscilam segundo os interesses perseguidos e as condições em que partem os grupos implicados numa relação interétnica. (Terrén, 2002, p. 31-32).

Cabe lembrar, também, de acordo com Terrén (2002), que já Robert Merton defendia $\curvearrowright$ que a etnicidade tinha se convertido numa \& questão de definição técnica. Na época, houve i um forte impulso no desenvolvimento empíri$\Rightarrow$ co da sociologia da etnicidade, com pesquisas qualitativas de caráter etnográfico, alentadas por uma reação antifuncionalista, que deixaram em evidência a "grande complexidade de um objeto que, raramente, pode ser observado no seu estado puro" e que acabou desencadeando o que Yinger chamou de "alargamento do significado de etnicidade".

De acordo com Poutignat e Streff-Fenart (2008), apesar das sólidas tentativas levadas adiante pelos antropólogos para desconstruir a noção de etnia, ela continua sendo pensada como um grupo portador de cultura, e a etnicidade como uma propriedade transmitida por herança cultural de um grupo pré-existente.

Em diálogo com essas perspectivas, ao definirmos o grupo aqui estudado como 'peruanas', buscamos, com isso, nomear elementos em comum de uma cultura de origem à qual pertencem as migrantes, que hoje se reforçam ao serem residentes num contexto fora do país de origem, a cidade de Brasília. Repare-se que, muitas vezes, nas falas das migrantes, elas fazem referência ao grupo com expressões tais como: "nós, peruanas, somos reconhecidas como boas cozinheiras".

Nesse sentido, não se busca justificar que a origem social e cultural comum seja essencial para delimitarmos um grupo com uma mesma pertença étnica, mas entendemos que, sim, são elementos relevantes e que se potencializam ao estarem "fora de casa". Note-se, também, que uma experiência de dominação comum - como em nosso caso o da exploração no âmbito do trabalho e a estigmatização sofrida - pode constituir, em si mesma, um fator decisivo para o sentimento de pertença comum e de unidade do grupo (Poutignat; StreffFenart, 2008).

Com base nesses autores, entendemos que a designação de "trabalhadoras domésticas migrantes/peruanas" não estaria definida em termos absolutos, nem racial nem etnicamente, mas sim, poderia sê-lo em termos relativos. Ou seja, tal categorização pode se tornar racial ou étnica pela significação outorgada pelos atores sociais envolvidos nas instâncias cotidianas de interação, segundo um determinado contexto.

Algumas vezes são elas próprias que dão essa conotação étnica à sua condição e à falta de oportunidades que eles sentem: 
Eu não quero que minhas filhas trabalhem em casa de família [a mais velha pedia para vir, pois também queria juntar dinheiro], eu quero que elas estudem, que sejam mais, e que não passem o que eu venho sofrendo, porque nossos pais eram camponeses. Nossos pais [fala em plural, pois inclui sua irmã Amelia] não falavam castelhano, só quéchua... Eu não queria que minhas filhas trabalhassem agora, quero que estudem, não quero que passem o que eu tenho sofrido por ter pais camponeses, analfabetos (Teresa).

Nós conhecemos as letras, mas os nossos filhos têm que ser mais que isso, não só conhecer as letras.... Precisam chegar a ser mais! (Amelia).

Fui fazer a documentação na Polícia Federal. Precisava fazer umas coisas pela Internet primeiro, para depois ir pagar no banco. Mas a gente não tinha feito isso. O policial perguntou "por quê?”. E eu disse: olha, a gente não sabe utilizar Internet, nós somos indígenas, olha aqui, eu uso tranças, por isso nós não sabemos... [risos!] Então, o policial nos disse, "tudo bem, eu faço para vocês, não se preocupem" (Amelia).

Portanto, parafraseando Poutignat e Streff-Fenart (2008), compreendemos que a nossa nomeação ao grupo estudado de "trabalhadoras domésticas migrantes/peruanas" não busca 'decretar' uma natureza étnica nem lhes impor uma forma de identidade. Ao invés, busca, através da perspectiva das próprias mulheres, reconhecer processos de identificação e de alterização que permitem identificar fronteiras sociais entre: "elas" e os empregadores, "elas" e os moradores da cidade (Brasília), "elas" e outras trabalhadoras domésticas.

Dito de outra forma, elas com elas próprias e com seu contexto de origem (seu presente, passado e futuro) e elas com as/os "outras/os" que constituem o seu presente vivido em Brasília, identificando nisso processos sociais de exclusão e de incorporação, definindo-se, assim, o que Barth (2008) denomina de fronteiras sociais étnicas.

Processos esses que levantam barreiras, sendo algumas delas explícitas e outras praticamente invisíveis, porém, muito efetivas. E a condição de gênero, i.e., o ser mulher, no caso que estudamos, entendemos constituir-se na base sobre a qual se sustenta o estigma tam- bém dotado das dimensões migratória, étnica, de classe e status, que mantém estas migrantes reféns à profissão de trabalhadora doméstica.

\begin{abstract}
A identidade de integrante de uma minoria é outorgada ao indivíduo como uma categoria de pertença estigmatizante, ligada visivelmente à pessoa pelos traços distintivos incorporados (a cor, a hexis corporal, o sotaque), ou marcas signaléticas (nome pessoal, lugar de moradia), naturalizados como atributos hereditários (dito de outra forma, uma "raça") e que engendram uma incapacidade de assumir as posições que todos os integrantes (majoritários e minoritários) consideram como de status chave na sociedade (Poutignat; Streff-Fenart, 2008, p. XVII) ${ }^{15}$
\end{abstract}

Significa dizer que consideramos que a dimensão de gênero conforma uma base à qual se sobrepõem outras dimensões da estrutura de opressão e discriminação em que esse grupo de migrantes vive antes e durante a experiência migratória; fenômeno que, no âmbito dos estudos de gênero, se denomina de "intersecionalidade" (Crenshaw, 2004; Piscitelli, 2008; de Sève, 2011) e que merece toda nossa atenção para esclarecermos que, a

[...] visão tradicional afirma: a discriminação de gênero diz respeito às mulheres e a racial diz respeito à raça e à etnicidade. Assim como a discriminação de classe diz respeito apenas a pessoas pobres. Há também outras categorias de discriminação [...] A intersecionalidade sugere que, na verdade, nem sempre lidamos com grupos distintos de pessoas e sim com grupos sobrepostos (Crenshaw, 2004, p. 9-10).

Em sociedades consideradas pós-coloniais, como as de nosso continente, a necessidade por muitos sentida de se livrar de algumas marcas estigmatizantes leva, inclusive, a uma autonegação, aspirando a introjetar na sua identidade elementos em certa forma "alheios", porém próximos até pela sua própria trajetória migrante (da aldeia/ da província para Lima, de Lima para Brasília). Já que, retomando Barth (2008), a etnicidade é definida pelas suas fronteiras, ou seja, pelos espaços de interação com os outros; e nós acrescentamos, seguindo a premissa interacionista, que ela também é ${ }^{15}$ Tradução nossa do original em francês. 
definida pelas instâncias de autointeração, que são muito dinâmicas, notadamente durante o processo de migração (Rivera, 1996).

No meu país também tem outra língua oficial, o quéchua, mas a maioria da população da cidade não sabe falar, nem aprende. Se você for para o interior, área rural, aí sim vai ouvir falar o quéchua e alguns também o Aymara. Mas eu nunca aprendi, pois nem preciso disso...

Aqui esta família com quem trabalho, eles comigo falam espanhol, mas entre eles falam francês... Eu gostaria muito de ir para França, e conhecer Paris! Conhecer... como é que se chama?... aquela torre... aquela famosa... não sei como pronunciar... mas tudo bem... por isso é quero ir...

Às vezes os escuto falar em francês e penso que seria bom eu tentar ouvir palavras e repetir para ir aprendendo. Mas eles falam tão rápido que nem dá para identificar uma palavrinha sequer. Eles falam, riem muito, acho que falam muitas piadas... E eu penso, que pena não poder entender! Pois assim eu também poderia rir, e acho chique essa língua.

A senhora me diz, "aprende francês" para poder vir com a gente para França... Mas, como? Onde? Quando que eu vou fazer isso?!?! Sinto vontade de lhe dizer: "senhora, você está pedindo algo que é impossível para mim”. No meu caso eu trabalho todos os dias, o dia todo... Meu sonho seria ao menos aprender o básico, para que, se me perdesse numa cidade como Paris, pudesse perguntar, onde fica tal rua?... essas coisas. Ou cumprimentar... o básico... Mas falar francês fluente é impossível nas minhas condições, nunca vou conseguir.

Eu penso que quando ela me diz isso é para eu ficar, para eu não ir embora. Porque aqui acontece muito de ter uma empregada e aí aparece um dia uma que está indo embora, que muda de emprego (Diana).

De acordo com a socióloga Silvia Rivera Cusicanqui (1996, p. 3), em um país como a Bolívia - e como extensão analítica o Peru e outros da nossa região -, a etnicidade precisa ser relacionada com as prolongadas marcas do colonialismo interno. ${ }^{16} \mathrm{E}$ isso vem conformando "caleidoscópicas e múltiplas etnicidades", sustenta a autora, que vão se articulando de forma

${ }^{16}$ O ‘colonialismo interno’ refere à reprodução da lógica opressora do colonizador para com os autóctones, entre os próprios colonizados. A cantautora e artista chilena Violeta Parra, em Arauco tiene una pena, sintetiza essa ideia da lógica colonizadora interna: "Arauco tiene una pena / más negra que su chamal / ya no son los españoles / los que los hacen llorar / hoy son los propios chilenos / los que les quitan su pan." muito diversa com níveis de renda, formas de consumo, e nós acrescentamos, também, status profissional e condição migratória. Por isso é que podemos falar em "identidades múltiplas e situacionais”; portanto, identidades dinâmicas, que vão se moldando e reinventando conforme as vivências durante esse percurso migratório.

Em decorrência disso, entendemos que o processo de autorreconhecimento, ou processo de individualização (Elias, 1994), sofre mudanças muito significativas quando se vive uma experiência forte como a da migração de mulheres a trabalho doméstico. Esse grupo de mulheres em Brasília possui uma história de migração muito específica, de separação da família e de "afastamento"17 da cultura de origem. Algumas hoje refizeram suas vidas na cidade, casaram e tiveram filhos, porém não é possível se despojar dessa experiência, mesmo que o balanço não seja necessariamente negativo. Esse seria o caso de Elena, hoje com residência permanente na cidade, casada com um peruano e com quatro filhos nascidos em Brasília.

Já outras, ainda sofrem por se sentirem detentoras de menos direitos que aqueles que possuíam no país de origem, devido à mudança identitária ocupacional, mas, ao mesmo tempo, pode-se identificar um sentimento de maior liberdade, graças à distância geográfica do modelo familiar patriarcal, ou por serem as principais fornecedoras de sustento material para sua família. A Carmen, por exemplo, passou de ser microempresária têxtil (confecção) em Lima para trabalhadora doméstica em Brasília. Ou seja, apesar de, por um lado, existir o sentimento de maior independência ou de autonomia econômica, porque já não precisam esperar o dinheiro do marido, do companheiro, por outro lado, muitas delas continuam subordinadas às decisões deles sobre como utilizar o dinheiro que elas ganham, situação justificada por elas próprias, com base nas necessidades dos filhos, ou, inclusive, nas necessidades de um namorado.

${ }^{17}$ Entre aspas, pois, consideramos que, durante o processo
migratório, se ressignifica o sentido do que é próximo e distante. 
Veja-se o relato de Maria, ao lembrar-se da família, do trabalho que desempenhava no Peru e do seu namorado antes e hoje:

Já faz 16 anos que meu pai morreu. Eu já tinha ido morar em Lima quando isso aconteceu. Na época minha mãe era muito nova, tinha 40 anos, e minha irmã mais nova só 5 anos. Eu decidi deixar minha carreira, pois a que tinha escolhido era muito cara... [curso técnico]. Eu já vendia roupa na rua, era "ambulante" [camelô], e aconteceu que um dia a polícia nos tirou da rua, nos mandou embora. Então comecei a alugar um pequeno espaço numa feira. Mas, como sempre, no início tudo era prejuízo.

E o meu namorado me dizia: "eu te pago teus estudos...”, mas eu não quis, parei de estudar, e agora ele me diz: "tá vendo, agora você é doméstica..."

Imagine... hoje eu teria meu próprio consultório particular... estudava prótese dentária. E além disso o instituto onde eu estudava tinha um convênio com a San Martin [universidade em Lima] para quem quisesse continuar fazendo odontologia depois.

Então, eu tenho que ficar hoje ouvindo meu namorado dizer: "olha só, você que queria ter seu próprio consultório ou trabalhar numa clínica... olha só, agora você que nunca pensou em ser doméstica... e que mandava lavar sua roupa fora de casa... que tinha quem lhe servir" (Maria).

Atualmente, Maria ainda mantém, como quase todas as migrantes do grupo estudado, uma relação de "fornecedora" (financeira) com o namorado, no sentido em que, hoje, é ela quem envia dinheiro para ele, mesmo sem ter o vínculo do casamento (convívio) ou de filhos em comum.

Estamos, portanto, perante um modelo de sociedade capitalista global que lhes oferece uma chance de trabalho muito específica (trabalho doméstico em Brasília, ou em outras cidades da região ou do hemisfério norte), justamente a elas, por serem mulheres pobres e desempregadas ou subempregadas.

\section{CLASSE, HONRA E STATUS: mar- cas femininas passadas e presentes}

A concentração de mulheres migrantes nos trabalhos do setor de serviços domésticos e de cuidados não só se explica pelas decisões por elas tomadas (projeto migratório, diferenças no nível do salário com relação ao país de origem, relações e contexto familiar), mas, também, resulta dos processos de seleção e de discriminação baseados na classe social, sexo, grupo étnico, status profissional ou migratório, que, por sua vez, se sustentam numa naturalização das diferenças (Comas D’Argemir, 2009, p. 184).

Para muitas, a tarefa de cuidar dos outros e da casa inicia-se desde criança, algo comum para as meninas nascidas em contextos como o do grupo aqui estudado.

Quando meu padrasto saía para trabalhar eu cuidava dos meus irmãos, mas eu era uma criança e não sabia da responsabilidade que tinha... Cuidei dos meus irmãos até os 14 anos junto com o meu padrasto (Lucía)

Ou seja, a origem social dessas mulheres migrantes aparece como um marcador que as distingue e as condiciona para desenvolver determinadas tarefas, como a de cuidar dos outros. Algo que o resto da sociedade, e até elas próprias, podem chegar a assumir como sendo uma tarefa natural por serem mulheres e pertencer a um determinado estrato social-étnico.

$\mathrm{Na}$ perspectiva weberiana as classes não são comunidades, mas bases possíveis e frequentes de ação comunal. Ou seja, existe uma classe quando o grupo em questão possui em comum um componente causal específico de suas oportunidades de vida, e, por sua vez, essa oportunidade está determinada: pela presença/ausência de um volume e tipo de poder, pela posse de bens ou habilidades passíveis de gerar rendimentos (Weber, 1969, p. 58-59).

Nesse sentido, o que as migrantes aqui estudadas, na situação de ausência total de propriedade de bens, têm a oferecer é o seu trabalho, acrescido da sua condição de migrante pobre, com pouca (ou inexistente) educação formal e sem família no Brasil que possa demandar tempo gerando tensões com a demanda de trabalho. Podemos estabelecer um diálogo entre essas condições em que se encontra o 
grupo de migrantes e aquilo que Weber (1969) denomina de "situação de classe". Pois, mesmo que possa parecer um paradoxo, consideramos que essas condições pouco vantajosas, ou situação de classe, que as caracteriza, se tornam uma vantagem competitiva no mercado de trabalho - a partir da perspectiva de certo tipo de empregador - quando se as compara com as trabalhadoras domésticas nacionais.

Note-se que o grupo aqui estudado mora ou já morou no lugar onde trabalha e tem poucas atividades fora desse espaço, fato que resulta num aumento da utilidade total sobre o serviço recebido pelo empregador em função das horas extras diariamente trabalhadas pelas mulheres sem remuneração adicional. Ainda que aconteça uma diminuição gradativa da utilidade marginal (i.e. a utilidade gerada pela qualidade do seu trabalho por cada hora a mais trabalhada), desde uma perspectiva unicamente economicista, resultará num maior benefício final para o empregador.

O meu quarto, não é meu quarto... nele só durmo... só posso entrar às 9 e meia ou 10 da noite, para deitar, acordo 6 da manhã... e só trabalho o dia todo. Faço o meu café da manhã em 10 minutos, e o meu almoço a mesma coisa... [Minha chefe] está o tempo todo me pressionando, pedindo coisas, acrescentando mais e mais. (Carmen)

Eu sinto asfixia de estar trancada. Preciso sair aos 느 finais de semana. Às vezes a gente está a fim de dorque Weber ([1922] 1944, p. 63) denomina de "poder de disposição", ou seja, a possibilidade de dispor, seja de fato ou garantida de qualquer outro modo (coerção, por exemplo), sobre a força de trabalho. Estamos perante uma relação assimétrica, onde se põe de manifesto o interesse de classe, um interesse que pode assumir diversas formas, já que se constitui pela interação e discussão das experiências cotidianas e as interpretações que delas se fazem (Bottomore, 2001).

Depois de um tempo com a família peruana, troquei de emprego. Fui trabalhar para uma diplomata brasileira durante vários anos. Tudo estava muito bem. Depois casei e fiquei grávida. Mesmo assim continuei trabalhando e cuidando da filha da diplomata, uma criança um pouco malcriada, mas com o tempo eu consegui dar conta. Na hora do nascimento do meu filho, a senhora me propôs mudar para Suíça junto com ela, para continuar cuidando da filha e da casa. Viajamos, mas... a situação foi piorando já que a menina estava com ciúmes do meu bebê. Ela, a senhora, começou a dizer que não estava dando certo, que não iria funcionar. Assim, pediu para eu retornar para Brasília, e voltei a morar com meu marido e cuidei do meu bebê (Mariana).

Quando conhecemos Mariana, a senhora diplomata estava prestes a retornar da Suíça. Mariana mantém uma relação boa com a senhora, segundo nos explicou, por isso lhe propôs voltar a trabalhar para ela, mas em Brasília. No entanto, Mariana esclarece:

Agora estou bem, claro que sinto muita falta de ter meu salário, contudo, isso de não ser mais a empregada de alguém me faz sentir bem, pois faço limpezas [diarista] sempre que surgem, mas não fico só numa casa. Também trabalho bastante na minha casa, eu cuido sozinha de tudo e, além disso, faço doces que vendo na vizinhança, ao menos para ter um dinheirinho meu (Mariana).

Vai se conformando, assim, uma ordem social onde a distribuição da "honra social" ou prestígio social (Weber, 1969, p. 58) deixa praticamente 'vazia' a profissão de trabalhadora doméstica. Contudo, salienta Weber (1969, p. 65), "[...] a honra de status não precisa necessariamente estar ligada a uma 'situação de classe”.

Por exemplo... agora estamos aqui [no Pontão ${ }^{18}$ ] e de todas as pessoas que estão nas outras mesas nenhuma percebe que eu trabalho em casa de família.

${ }^{18}$ Área de lazer na beira do Lago Paranoá em Brasília, que Carmen conheceu pela primeira vez depois de três anos trabalhando na cidade, na ocasião de um de nossos encontros. 
Neste momento eu sou uma a mais no grupo que aqui está (Carmen).

Eu já rejeitei um emprego porque a senhora queria me obrigar a usar uniforme. Olha, as chefes peruanas [foi uma entrevista para trabalhar com uma família peruana] adoram isso, fazem questão que a gente esteja de uniforme. Sabe por quê? Porque elas têm medo que as visitas da casa não percebam quem é a senhora e quem é a empregada (Carmen).

No cotidiano do trabalho, não só se dá uma luta pela sobrevivência e pela realização de projetos e sonhos, mas, também, em algumas delas há uma angústia pela falta de igualdade de "estima social" (Weber, 1969, p. 65). No dia-a-dia sentem, sofrem e isso parece alimentar muito mais a motivação em recuperar certo prestígio social no país de origem para elas próprias e para a família. É como se, em Brasília, já não houvesse chances enquanto continuarem a trabalhar no serviço doméstico. E mudar de emprego parece algo impossível.

Trabalhar, lutar hoje para outorgar - e em alguns casos devolver - essa honra e estima social aos filhos e filhas, assim como, também, às vezes, ao marido/companheiro, através do envio de dinheiro para que estudem, para que consumam e, assim, depois, no futuro (aquilo com que elas sonham), voltar e 'usufruir' dessa honra que não tinham ou não têm. Trabalhar em Brasília torna-se o meio de obter ou recuperar um status, independentemente de que isso possa vir a acontecer ou não.

Quando eu voltar, vou pedir para minhas duas últimas chefas fazerem uma carta de recomendação, mas como cozinheira e não como empregada doméstica. Não é por mentir, mas sei que lá [no Peru] isso me dá outro lugar do que dizer que em Brasília eu fui empregada doméstica. Melhor dizer que eu trabalhei como cozinheira de diplomatas (Maria)

Dentro do que possamos identificar como uma mesma classe social estaria a profissão de trabalhadoras domésticas, cozinheiras em casas de famílias, jardineiros, etc. Porém, existem nuances, da mesma forma que acontece com outros grupos sociais, que se referem ao desenvolvimento do status que, na linha de Weber (1969, p. 67), entendemos tratar-se de uma questão de estratificação baseada na usurpação.

Ou seja, no cotidiano do trabalho, essas migrantes relatam momentos de orgulho quando são elogiadas pelos convidados dos chefes pela qualidade do jantar que elas preparam. Haveria certas tarefas associadas a recompensas especiais pela possibilidade de interagir com convidados detentores de um altíssimo grau de honra e estima social (ministros, diplomatas, por exemplo). E, de acordo com elas, isso as torna especiais e diferentes da trabalhadora doméstica brasileira. Assim, cozinhar para jantares ou eventos importantes lhes devolve certo status "usurpado" durante a maior parte do seu tempo de trabalho e, às vezes, também no tempo de lazer.

Significa dizer que, nem sempre, elas se sentem "desacreditadas" ou estigmatizadas; por momentos, algumas sentem que conseguem passar à categoria das pessoas "desacreditáveis”, servindo-nos de conceitos goffmanianos. Ou seja, na hora da interação, seja no âmbito do trabalho ou de instâncias de lazer, as migrantes, como qualquer pessoa, buscam manipular a informação sobre aquilo que as "marca" socialmente. Evidentemente que as possibilidades reais de manipular tal informação muitas vezes são poucas, pois há as características daquilo que não pode ser escondido: os traços físicos, o jeito de falar ou vestir, por exemplo.

Quando estava esperando a Amelia chegar, fiquei sentada num ponto de ônibus, sabendo que nesse já não param os ônibus. Parece que era um ponto antigamente, mas agora já não mais. Aí... eu via as pessoas passar caminhando e olhavam para mim. Todo mundo passava e olhava, mas ninguém falava nada... Eu comecei a rir e pensava, "esses brasileiros devem estar pensando 'coitada dessa indígena, ela não sabe que aqui não passam mais ônibus”'[risos!] Mas é claro que eu sei! (Teresa)

Por isso Goffman (1988, p. 53) chama essa informação de "social”, pois ela:

[...] assim como o signo que a transmite, é reflexiva e corporificada, ou seja, é transmitida pela própria pessoa a quem se refere, através da expressão corporal na presença imediata daqueles que a recebem. 
[...] A informação social transmitida por qualquer símbolo particular pode simplesmente confirmar aquilo que outros signos nos dizem sobre o indivíduo, completando a imagem que temos dele de forma redundante e segura.

Repare-se que, no exemplo dado por Teresa, não são "os brasileiros", cidadãos do local, que olham para ela e pensam: "coitada dessa indígena”. Essa é a leitura que a própria Teresa [sujeito da suposta estigmatização] faz do que os outros estariam interpretando. Para além de estigmatizar-se, ela também estigmatiza o outro que ela identifica como "os brasileiros”. Pois, na sua leitura, eles, olhando para ela, estavam demonstrando sentir compaixão e ignorar que ela já sabe e domina essa informação do local.

Retomando nossa reflexão sobre a usurpação do status que afeta à profissão de trabalhadora doméstica, cabe salientar que as habilidades como a de ser boa cozinheira, que caracteriza muitas migrantes peruanas que trabalham neste setor, são valorizadas no mercado de trabalho como sendo inatas a pessoas dessa origem social e cultural. Ou seja, não seria, neste caso, um reconhecimento a um tipo de qualificação formal, mas um reconhecimento a algo esperado já delas, por serem mulheres, trabalhadoras domésticas e peruanas, i.e. um L2 estigma que se justifica pela sua origem e conจे dição social e de gênero.

\section{CONCLUSÃO}

Cada uma das dez mulheres desse grupo de migrantes faz da sua ação de migrar um meio para mudar suas vidas. A decisão de migrar é tomada por elas, segundo nos relatam, mas, também, como consequência de um contexto familiar que se apresenta passivo perante os problemas de falta de emprego e carências materiais. Esse contexto familiar, fortemente androcêntrico, lhes outorga o lugar na família de ser as que sustentam e as que saem para tentar "salvar" o grupo familiar de problemas materiais que enfrenta. Isso porque, segundo as migrantes, para a mulher é mais fácil migrar, pois, devido a práticas culturais, há maiores chances de achar emprego no setor de trabalho doméstico nos lugares de destino.

As mudanças esperadas na vida dessas mulheres podem acontecer diretamente com elas, assim como indiretamente, através do potencial de mudança de vida que possam deter outros integrantes da família (filhos, maridos, etc.) a quem elas enviam o dinheiro produzido por seu trabalho. A contribuição monetária enviada à família na origem dá-lhes condições de acesso ao consumo de bens materiais (tangíveis) tais como a reforma da casa familiar e a compra de eletrodomésticos, produzindo-se uma forte expectativa de mudança do status familiar no âmbito da comunidade de origem. Ao mesmo tempo, pode contribuir, também, para a aquisição de um capital cultural mais sólido, através da possibilidade de acesso à educação formal de filhos que permanecem dependentes dessas mulheres migrantes.

O sonho de muitas delas é um dia ver seus filhos sendo profissionais, pessoas "bem de vida", tendo um status social diferente ao de suas mães e, consequentemente, que lhes permita "usufruir" dessa vida "bem sucedida". A nossa pesquisa mostra que há distâncias entre o projeto de vida que sustenta a decisão de migrar e a sua efetiva realização, que, muitas vezes, encontra limites objetivos de realização. Assim, nem sempre, por exemplo, vão dar conta de "empoderar" seus filhos no grau que elas esperam, ou de abrir o pequeno negócio e se tornarem microempresárias - segundo podemos interpretar nos seus próprios relatos. Essa constatação comprova, sem dúvida, que migrantes não são "aventureiros", são indivíduos que elaboram um projeto de vida, que, geralmente, pressupõe inserção efetiva na lógica do sistema tanto para si como para familiares. São, então, indivíduos inseridos numa estratégia social mais do que individual.

Observamos que, em todas as migrantes, há uma atitude de renúncia no tempo presente 
para obter a estima social tão desejada no tempo futuro, incluindo as que moram com suas famílias em Brasília. Nenhuma delas considera que sua vida, no momento presente, seja do jeito que elas esperavam, pois todas, ao falar dos seus sonhos, o fazem através dos filhos (as que são mães) ou projetando mudanças consideráveis de vida.

Por outro lado, observamos que a vida profissional desse grupo de mulheres - o status de trabalhadoras domésticas, diarista - não dá conta do processo de autoidentificação por elas introjetado como sendo socialmente valorado e detentor de estima social. Tais valorações provocam um maior dinamismo no processo identitário que, nesse caso, se intensifica pelo sentimento de vazio de honra com relação a sua identidade ocupacional, gerando o que a socióloga Silvia Rivera (1996, p. 3) chama de "identidades múltiplas e situacionais".

Ou seja, não só identificamos uma multiplicidade na autoidentificação - "camponesa”, “indígena”, "peruana”, "excelente cozinheira”, "mãe”, "estrangeira”, "mulher pobre”, "desempregada", "namorada" - como, também, observamos nisso os efeitos daquilo que, nos estudos de gênero, se denomina de "intersecionalidade”. Isto é, a sobreposição de condições de vida estigmatizantes e que referem a uma dimensão de gênero por cima da qual se sobrepõem a dimensão étnica, de classe e de status: ser mulher, migrante, pobre, com dificuldades de obter documentação, traços indígenas, carente de educação formal ou sancionada pela sociedade, ter dificuldades com a língua, ser pouco conhecida na cidade, além de carregar um sentimento de muita solidão.

Recebido para publicação em 28 de julho de 2014 Aceito em 29 de novembro de 2014

\section{REFERÊNCIAS}

BARTH, Fredrik. Les groupes ethniques et leurs frontières. In: POUTIGNAT, Philippe; STREFF-FENART, Jocelyne. Théories de l'ethnicité. Paris: Quadrige, PUF: 2008. p. 203-249.
BOSI, ECLÉA. Memória e sociedade. Lembranças de Velhos. São Paulo: Companhia das Letras, 1994.

BOTTOMORE, Tom (ed.). Dicionário do pensamento marxista. Rio de Janeiro: Jorge Zahar Ed., 2001.

BLUMER, Herbert. The methodological position of symbolic interactionism. In: Symbolic ineractionism: perspective and method. USA: Prentice-Hall, 1998 [1937]. p. 1-60.

COMAS D'ARGEMIR, Dolors. Trabajo, economia sumergida y género. La atención a la dependencia. In: TÉLLEZ INFANTES, A.; MARTÍNEZ GUIRAO, J.E. (eds.). Economía informal y perspectiva de género en contextos de trabajo. Barcelona: Icaria, 2009. p.169-195.

CRENSHAW, Kimberle W. A intersecionalidade na discriminação de raça e gênero. 2004. Disponível em: http://www.acaoeducativa.org.br/fdh/wp-content uploads/2012/09/Kimberle-Crenshaw.pdf. Acesso em: 30 jan. 2014.

DE SÈVE, Micheline. L'intersectionnalité: féminisme enrichi ou cheval de Troie? Labrys, études féministes, juillet/décembre, 2011, n²0-21, Disponível em: http:// www.tanianavarroswain.com.br/labrys/labrys 20/franco/ micheline.htm. Acesso em: 07.01.2012.

DUTRA, Delia. Migração internacional e trabalho doméstico. Mulheres peruanas em Brasília. Brasília: CSEM; Sorocaba, SP: OJM, 2013.

ELIAS, Norbert. A sociedade dos indivíduos. Rio de Janeiro: Zahar, 1994

FONTENLA, Marta Amanda. Patriarcado. In: Diccionario de estudios de género y feminismos. Buenos Aires: Biblos, 2007, p. 256-258.

GOFFMAN, Erving. Estigma. Notas sobre a manipulação da identidade deteriorada. Rio de Janeiro: Guanabara, 1988.

GRANAI, Georges. Técnicas de investigación sociológica. In: GURVITCH, G. (dir). Tratado de sociologia. Buenos Aires: Kapelusz, 1962, p. 153-172.

HALBWACHS, Maurice. A memória coletiva. São Paulo: Vértice, 1990. [1950].

Les cadres sociaux de la mémoire. Paris: Albin Michel, 1994. [1925]

HARRISON, Regina. La canción quechua: simbología e ideología de la mujer andina. Cuadernos Hispanoamericanos. n. 417, Marzo, 1985. p. 11-25.

HIRATA, Helena. XI Conferência regional sobre a mulher de América Latina e do Caribe, Painel "Emprego, responsabilidades familiares e obstáculos socio-culturais à igualdade de gênero na economia”. Conferência da Profa. Dra. Helena Hirata, Brasília, 14 de julho de 2010. Mimeo.

IOM Gender and Migration News, April 2010, Disponível em: http:/iom.int/jahia/webdav/site/myjahiasite/shared/ shared/mainsite/published_docs/periodicals_and newsletters/gender_bulletin_apr10.pdf. Acesso em: mai. 2010.

LUMBRERAS, Luis Guillermo. Perú: segregación racista y marginalidad clasista. In: RIQUELME, H.U. Buscando América Latina: identidad y participación psicosocial. Caracas: Nueva Sociedad, 1990. p. 57-68.

MONTANER, Carlos Alberto. Las raíces torcidas de América Latina. Barcelona: Plaza \& Janés Editores, 2001.

NUNES, Brasilmar F. (org.) Brasília: a fantasia corporificada. Brasília: Paralelo 15, 2004

OIT. Manual de capacitação e informação sobre gênero, raça, pobreza e emprego: guia para o leitor. Questão racial, pobreza e emprego no Brasil: tendências, enfoques e políticas de promoção da igualdade. Brasília: OIT, 2005. 
PISCITELLI, Adriana. Interseccionalidades, categorias de articulação e experiências de migrantes brasileiras. Sociedade e Cultura, jul.|dez. 2008, n. 2 v. 11, p. 263-274.

POUTIGNAT, Philippe; STREFF-FENART, Jocelyne. Théories de l'ethnicité. Paris: Quadrige, PUF: 2008.

RIVERA, Silvia C. Desafios para uma democracia étnica y de gênero en los albores del tercer milenio. In: RIVERA, S. C. Bircholas. Trabajo de mujeres: explotación capitalista y opresión colonial entre las migrantes aymaras de La Paz y El Alto. La Paz, Bolivia: Mama Huaco, 1996. p. 01-69.

SALA, Gabriela Adriana. Perfil educativo y laboral de los nuevos y viejos migrantes regionales censados en Argentina y Brasil. Migraciones Internacionales, v. 4, Núm.4, Julio-Diciembre de 2008. p. 73-106.

SARLO, Beatriz. Tempo passado. Cultura da memória e guinada subjetiva. São Paulo: Companhia das Letras; Belo Horizonte: UFMG, 2007.
TERRÉN, Eduardo. El análisis de la cuestión racial en el desarrollo de la sociología. In. TERRÉN, Eduardo (ed). Razas en conflicto. Perspectivas sociológicas. Rubí, Barcelona: Anthropos, 2002, p. 7-41.

THIOLLENT, Michel. Crítica metodológica, investigação social e enquete operária. São Paulo: Polis, 1987.

WEBER, Max. Classe, Status, Partido. In: Bertelli, A.; PALMEIRA, M.; Velho, O. (Orgs.). Estrutura de classes e estratificação social. Rio de Janeiro: Zahar, 1969, p. 57-75.

. Economia y sociedad. 1a edição [1922]. México: Fondo de Cultura Económica, 1944, Vol. I.

WOORTMANN, Klaas. Religião e ciência no renascimento. Brasília: Ed. Universidade de Brasília, 1997. 


\section{SIGNS OF ORIGIN AND PROFESSION: Peruvian domestic workers in Brasilia}

\section{Delia Dutra}

The present article analyzes how does a group of Peruvian women, domestic workers, experience their migratory experience in Brasilia. The analysis is made in an interactional perspective - with an emphasis on the spheres of gender, ethnicity and class - trying to understand the social integration processes of those migrants in a city with unique urban and historical characteristics in Brazil and in that region. The in-depth interviews allow us to reflect on how they explain their integration with the city, the everyday life at work; that is, we analyze how do they produce their life space in migration. We are able to establish, in that condition of migration to work, a range of elements that compete for the production of that space: cultural and social origin, social gender relations inside and outside the family nucleus, among others. We identified a strong lack of honor and an absence of social esteem associated by the migrants themselves to the profession of domestic worker.

KEywords: Peruvian women. Brasilia. Domestic work. Routine interactions.

\section{LES MARQUES D'UNE ORIGINE ET D'UNE PROFESSION: employées de maison péruviennes à Brasilia}

\section{Delia Dutra}

L'analyse présentée dans cet article démontre comment un groupe de femmes péruviennes, employées de maison, vivent leur expérience migratoire à Brasilia. Cette analyse est faite dans une perspective interactionniste-en mettant l'accent sur les dimensions de genre, ethnique et de classe - ce qui permet de comprendre les processus d'intégration sociale de ces migrants dans une ville qui a des caractéristiques historiques et urbaines particulières au Brésil et dans la région. Les interviews approfondies permettent de réfléchir à la manière qu'elles ont d'expliquer leur intégration dans la ville, leur quotidien au travail. En d'autres termes, nous avons pu analyser comment elles construisent leur espace de vie en migration. Cela nous a permis de constituer, dans le cadre de la migration pour le travail, une série d'éléments qui contribuent à la production de cet espace: l'origine sociale et culturelle, les relations sociales de genre au sein et en dehors du noyau familial, entre autres. Nous avons identifié une absence de fierté et un manque d'estime sociale associés à la profession d'employée de maison par les migrantes ellesmêmes.

Mots-CLÉs: Femmes péruviennes. Brasilia. Travail des employées de maison. Interactions quotidiennes.

\footnotetext{
Delia Dutra - Doutora em Sociologia pela Universidade de Brasília. Professora Colaboradora Plena e Bolsista do Programa Nacional de Pós-Doutorado (PNPD/CAPES) no Programa de Pós-Graduação em Estudos Comparados sobre as Américas (CEPPAC), Universidade de Brasília. Pesquisadora do Observatório das Migrações Internacionais e do Laboratório de Estudos sobre Migrações Internacionais (LAEMI). Coordenadora do Grupo de Estudos Interdisciplinares sobre Gênero(GRIEG/LAEMI/CEPPAC). Desde 2007 colabora com o Centro Scalabriniano de Estudos Migratórios, CSEM em Brasília. Suas principais áreas de estudo são: sociologia das migrações e das relações sociais de gênero. Publicações recentes: A dimensão comunicacional como recorte metodológico para o estudo das migrações, Revista Latinoamericana de Comunicación Chasqui, 2014, em co-autoria (Russi, Pedro e Dutra, Delia); Mulheres, migrantes, trabalhadoras: a segregação no mercado de trabalho, REMHU, 2013; Mulheres do sul também migram para o sul, Anuario Americanista Europeo, 2013; Migrações Internacionais e Trabalho Doméstico. Mulheres peruanas em Brasília, 2013.
} 
